OPEN ACCESS

Edited by:

Michele D'Amato,

University of Basilicata, Italy

Reviewed by:

Antonio Formisano,

University of Naples Federico II, Italy

Francesco Clementi,

Marche Polytechnic University, Italy

Raffaele Laguardia,

Sapienza University of Rome, Italy

*Correspondence:

Nicola Tarque

sntarque@pucp.edu.pe

Specialty section:

This article was submitted to

Earthquake Engineering,

a section of the journal

Frontiers in Built Environment

Received: 29 January 2020

Accepted: 31 March 2020

Published: 08 May 2020

Citation:

Sumerente G, Lovon H, Tarque N and Chácara $C$ (2020) Assessment

of Combined In-Plane

and Out-of-Plane Fragility Functions for Adobe Masonry Buildings

in the Peruvian Andes.

Front. Built Environ. 6:52.

doi: 10.3389/fbuil.2020.00052

\section{Assessment of Combined In-Plane and Out-of-Plane Fragility Functions for Adobe Masonry Buildings in the Peruvian Andes}

\author{
Giovanni Sumerente, Holger Lovon, Nicola Tarque* and César Chácara \\ Department of Engineering, Pontificia Universidad Católica del Perú, Lima, Peru
}

In the city of Cusco and in other parts of Peruvian Andes, adobe masonry is the primary construction material. Adobe continues to be used for the construction of housing because of its low cost, its thermal properties, the use of unskilled labor, and the local traditions of the Peruvian highlands. The Peruvian National Statistics Office estimates that $67 \%$ of rural housing in Cusco is made of adobe masonry. Besides, previous seismic events and laboratory tests demonstrated that adobe dwellings without reinforcement are prone to collapse during an earthquake. Therefore, seismic vulnerability assessment of this type of dwellings is necessary aiming at developing proper contingency and mitigation risk policies. Then, fragility curves constitute a key tool when conducting seismic loss assessment because they provide information regarding the probability of exceeding a certain damage limit state as a function of a given engineering demand parameter. This work aims at developing fragility curves, combining in-plane and outof-plane loading conditions, for typical adobe buildings located in the city of Cusco. Initially, a set of one- and two-story adobe houses were studied to determine the geometrical characteristics of representative local building typologies. Subsequently, 1,000 artificial buildings were generated by means of Monte Carlo simulation based on the information gathered. The structural capacity of each artificial building was represented by simplified bilinear and trilinear capacity curves for in-plane and out-ofplane mechanisms, respectively. In order to represent the characteristics associated with subduction processes, a set of ground motion records was established. The damage state of each building was assessed for each seismic record, and this information was collected into a Probability Damage Matrix (DPM). Finally, fragility curves were fitted for each damage state of the cumulative DPM. Preliminary results show that one- and twostory adobe dwellings have a probability of collapse of 30 and $60 \%$, respectively, when considering a peak ground acceleration of $0.30 \mathrm{~g}$, which corresponds to the expected acceleration related to a return period of 475 years over a soil type 2 according to the Peruvian Standards.

Keywords: adobe, seismic vulnerability, capacity curves, out-of-plane failure, in-plane failure 


\section{INTRODUCTION}

Fragility assessment constitutes an important component when determining the seismic risk of a region because it is capable of measuring how prone buildings are to suffer damage due to a given intensity of ground motion (Borzi et al., 2008). Seismic vulnerability assessment is usually focused on structures characterized by the presence of rigid diaphragms whose global response is ruled by in-plane mechanisms. Nevertheless, this is not the case of adobe masonry buildings because their structural performance is given by the combination of in-plane and outof-plane mechanisms due to the lack of a box-type behavior. This particular response has been observed in previous earthquakes, as well as in laboratory tests (Ahmad et al., 2011; Tarque et al., 2012).

The present investigation focuses on the seismic vulnerability assessment of one- and two-story adobe dwellings located in the city of Cusco, Peru. For this purpose, Probability Damage Matrices (DPMs), together with fragility curves, are developed for these structures considering two types of failure mechanisms: in-plane and out-of-plane. For this, it is necessary to determine capacity curves for each mechanism and for each building. On the one hand, the capacity for the in-plane mechanism can be adequately represented by a collapse multiplier developed by Benedetti and Petrini (1984). Such multiplier has been used in different methodologies such as the VULNUS method proposed by Bernardini et al. (1990) for masonry buildings, the FaMIVE method by D'Ayala and Speranza (2002) for historical constructions, in Cosenza et al. (2005) for reinforced concrete constructions. In addition, the simplified pushoverbased earthquake loss assessment (SP-BELA) method has also been applied for masonry structures as reported by Borzi et al. (2008). There are other investigations that use a similar methodology, such as Crowley et al. (2004); Vicente et al. (2011), Neves et al. (2012); Formisano et al. (2017), Villar-Vega et al. (2017); Lovon et al. (2018), Chieffo and Formisano (2019), and Chieffo et al. (2019). On the other hand, the capacity associated with out-of-plane mechanisms has been evaluated by means of a trilinear displacement versus force curve. This curve was proposed by Doherty et al. (2002) and further evaluated by Griffith et al. (2003), for the evaluation of rocking of masonry walls without reinforcement. It is important to notice that historic buildings are not evaluated in the present work; these kinds of structures need other considerations in their analysis, as are described in Briceño et al. (2019) and Fuentes et al. (2019).

In this research, the seismic vulnerability of unreinforced adobe masonry dwellings has been evaluated considering the combination of in-plane and out-of-plane collapse mechanisms. For this purpose, a random sample of adobe buildings was generated using the Monte Carlo simulation. The generation of this synthetic database is based on a detailed survey carried out to define geometrical characteristics of typological adobe buildings. Furthermore, the capacity of each building was calculated by the definition of simplified bilinear and trilinear capacity curves, respectively. The analysis combines both capacity curves, which were compared with the seismic demand, computed from records that represent the seismicity of the studied area. Based on the performance of each synthetic buildings. Probability Damage
Matrices were developed, and subsequently, analytical fragility curves were properly derived.

\section{METHODOLOGY}

Crowley et al. (2004) classify the methodologies for vulnerability assessment in three categories: empirical, hybrid, and analytical. In the empirical method, the assessment is based in the damage observed from past earthquakes, making use of the DPM and the vulnerability functions based on expert judgment. In the hybrid method, the DPM and vulnerability functions combine postearthquake damage statistics with simulations. The analytical method convolves the ground motion demand and capacity of the stock of buildings; the capacities are modeled analytically. Considering the variation in capacity and demand, the probability of being or exceeding limit states (LSs) are defined. This work used the analytical method to obtain the fragility curves.

On one side, seismic vulnerability assessment is often oriented to evaluate the uncertainty in the response of a given structural class. This procedure may require the analysis of a large number of buildings, which constitutes an arduous and long-lasting task. It is because of that fast analysis methodologies were adopted. On the other side, the geometrical and mechanical properties of the building class should be properly represented. In this way, field surveys play an important role. A field survey was carried out in some zones of Cusco city to gather information of one- and two-story buildings. This survey allowed the statistical characterization of adobe buildings, namely, mean value, standard deviation, and probability density function. A synthetic sample was generated using Monte Carlo simulation.

The in-plane mechanism was evaluated using the SP-BELA methodology; this uses the collapse multiplier and the LSs. On the other hand, the out-of-plane behavior was represented by a displacement-lateral force curve assessed according to Doherty et al. (2002). The displacement method (Silva et al., 2013) is adopted to define if a dwelling will survive or not to a given input motion. The general idea is to compare the capacity displacement with the spectral displacement demands, obtained from a group of seismic records. Special attention is done to the out-of-plane actions because it is the first mechanism to analyze. If the building does not collapse under out-of-plane, then the in-plane capacity is evaluated for each LS. This procedure allows to have combined fragility curves considering both failure mechanisms.

\section{TYPOLOGY OF ADOBE BUILDINGS}

The characterization of the building stock in Cusco was carried out through fill surveys. Those were prepared in such a way to collect important information as number of stories, dimension of walls and openings, roof system, and wall distribution, among others. The surveys were developed for one- and two-story buildings because the adobe dwellings located in such area are usually built up to two levels (Figure 1).

Aiming at assessing the seismic vulnerability of this type of structures, 13 and 22 adobe dwellings were surveyed for one- 
and two-stories, respectively. Based on these surveys, it was possible to determine the statistical characteristics of the main geometrical parameters that influence their seismic behavior. It is worth to note that walls, including the presence of door or window openings, with a length less than $1 \mathrm{~m}$ were not considered in this investigation because they may not present a significant contribution to the shear strength of the structure. In addition, it was observed that some two-story buildings were characterized by the presence of quincha walls for the division of large areas (Figure 2). These walls are composed of a timber frame filled with intertwined cane and mud, and they presented a maximum thickness of $0.15 \mathrm{~m}$. For this investigation, the quincha walls were considered as an additional mass to the buildings, but its contribution to the global strength of the structure was neglected. In the two-story dwellings, the timber diaphragm was composed of wooden floor joist distributed along the shortest direction, on these rest a tongue-and-groove floor. This type of floor system does not increase significantly the lateral stiffness of the structure because it constitutes as a flexible diaphragm. All the walls parallel to the facade were considered in the $Y$-axis, and the perpendicular walls in the $X$-axis.

After the adobe dwellings were surveyed, the collected information was processed, allowing the statistical

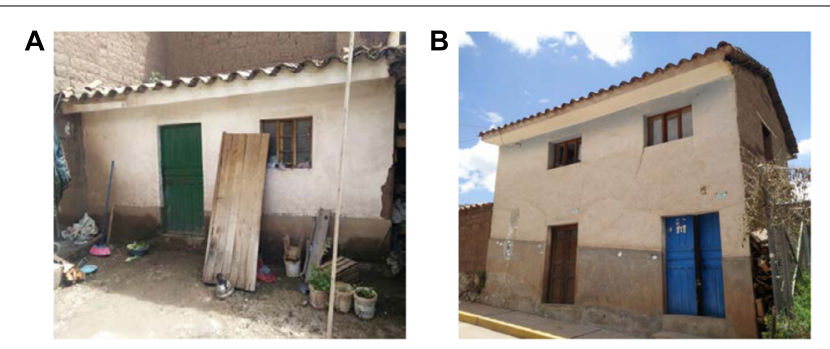

FIGURE 1 | Typical surveyed buildings. (A) One- and (B) two-story adobe dwellings.

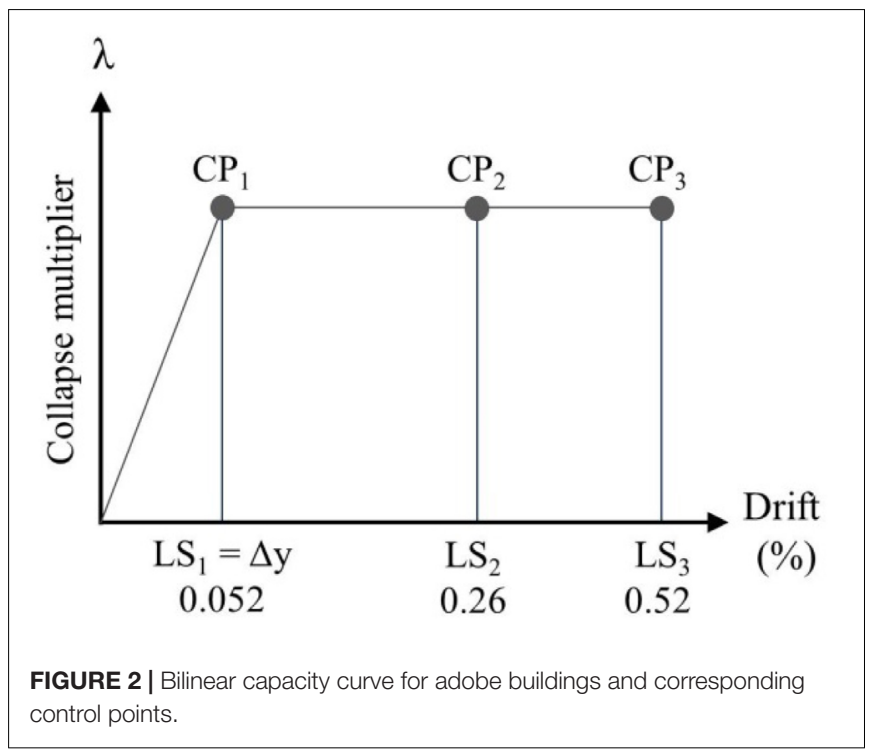

characterization of adobe buildings. For instance, the mean value of the wall thickness was $0.5 \mathrm{~m}$, whereas the average height for buildings was 2.5 and $4.9 \mathrm{~m}$ for one- and two-story buildings, respectively. It was also evidenced that the constructed area for one-story dwellings presented a mean value of $38.8 \mathrm{~m}^{2}$. In the case of two-story dwellings, this value increased to $50.50 \mathrm{~m}^{2}$. A summary of the parameters defined for this investigation, together with their corresponding mean value $(\mu)$ and standard deviation $(\sigma)$, is reported in Table $\mathbf{1}$.

\section{STRUCTURAL CAPACITY ASSESSMENT}

The behavior of masonry structures characterized by a flexible diaphragm is governed by in-plane and out-of-plane failure mechanisms. However, Borzi et al. (2008) reported that previous earthquakes have demonstrated that there is no interaction between these mechanisms because one can occur despite the other, and therefore, it can be assumed that these responses are uncoupled. In this sense, the assessment of the seismic vulnerability of the adobe dwelling required the definition of independent capacity curves for each mechanism, together with the corresponding damage LSs.

\section{In-Plane Failure Mechanism}

The structural capacity of a building can be properly represented through a pushover failure mechanism, which relates the base shear force due to the distribution of lateral forces and the displacement at a control point (Borzi et al., 2008). From a probabilistic point of view, an accurate estimation of the structural capacity of a building is not usually required; hence, simplified approaches, such as the SP-BELA method, are frequently used to determine the capacity curve of structures. The application of these simplified approaches provides results with a reasonable accuracy when compared to those obtained by means of more sophisticated methodologies and with a significant reduction of the computational effort for the estimation of capacity curves. A bilinear pushover curve represents the response of adobe masonry structure subjected a cyclic test (Tarque et al., 2012; Montesinos, 2016).

The objective of structural analysis is to determine the level of damage of a structure, which is usually measured in terms of the lateral displacement or interstory drift. In order to carry out the evaluation, limits are established; thus, the damage assessment

TABLE 1 | Identification of uncertain parameters and statistical characteristics.

\begin{tabular}{|c|c|c|c|c|c|c|}
\hline \multirow[t]{2}{*}{ Parameter } & \multirow[t]{2}{*}{ Symbol } & \multirow[t]{2}{*}{ Unit } & \multicolumn{2}{|c|}{ One-story } & \multicolumn{2}{|c|}{ Two-story } \\
\hline & & & $\mu$ & $\sigma$ & $\mu$ & $\sigma$ \\
\hline Wall density in $\mathrm{X}$ direction & $\rho_{X}$ & - & 0.17 & 0.07 & 0.16 & 0.04 \\
\hline Wall density in $Y$ direction & $\rho_{Y}$ & - & 0.17 & 0.10 & 0.12 & 0.02 \\
\hline 1st story height & $h_{1}$ & $\mathrm{~m}$ & 2.47 & 0.24 & 4.92 & 0.47 \\
\hline 2nd story height & $h_{i}$ & $\mathrm{~m}$ & - & - & 2.46 & 0.23 \\
\hline Area & $A_{T}$ & $m^{2}$ & 38.83 & 26.60 & 50.50 & 26.85 \\
\hline Wall thickness & $t$ & $\mathrm{~m}$ & 0.46 & 0.05 & 0.49 & 0.04 \\
\hline
\end{tabular}


can be carried out in a discrete manner. When a structure is subjected to a lateral force, it develops displacements that define its strength and level of damage. Three possible drifts are considered as points of control (CP), which are related to the LSs and are defined as follows: light damage, moderate damage and collapse (Figure 3). Based on Borzi et al. (2008), after the earthquake occurred, in the light damage $\left(L_{1}\right)$, the building can be used without repair or reinforcement. In the significant damage $\left(\mathrm{LS}_{2}\right)$, the building can be used whenever reinforcement has been done, which means a high cost in the repair. In the collapse $\left(\mathrm{LS}_{3}\right)$, the building is not able to resist lateral forces and even loads of gravity, resulting unsafe for the inhabitants.

The limiting conditions for adobe constructions have been identified by experimental tests; the damage has been related to a drift capacity. The LS values obtained for adobe walls from incremental displacement tests carried out by Tarque et al. (2012) are indicated in Figure 3. Control points identify important stages in the in-plane behavior of masonry buildings: $\mathrm{CP}_{1}$ is considered the limit elastic where the building is nearly undamaged and cracks up to $0.3 \mathrm{~mm}$ thick; in $\mathrm{CP}_{2}$, the building is extensively damaged but repairable with horizontal cracks beginning and new cracks up to $1.6 \mathrm{~mm}$ thick, and in $\mathrm{CP}_{3}$, the collapse is expected with cracks larger than $5 \mathrm{~mm}$ thick.

The representation of the capacity curve is given by a lateral force versus displacement graph. The SP-BELA method by Borzi et al. (2008) proposes the use of an equivalent system, thus reducing the system of multiple degrees of freedom (MDOFs) to a system of a single degree of freedom (SDOF) equivalent in terms of mass, stiffness, and displacement capacity. To define the displacement capacity of the equivalent structure, it is necessary to assume a deformation for each LS. Figure 4, which was built according to Borzi et al. (2008), illustrates these considerations for a two-story building. In MDOF, $m_{i}$ is the mass considered in a story height $h_{i}$, the soft mechanism is predicted within a height $h_{p}$ and $h_{T}$ is the total height of the building; $h_{e}$ and $m_{e}$ is the equivalent height and the equivalent mass, respectively, in SDOF.

When the deformation of the structure is elastic, it is considered a linear form. The first control point $\left(\mathrm{CP}_{1}\right)$ is determined by the following expression:

$$
\Delta_{y}=k_{1} \cdot h_{T} \cdot \delta_{y}
$$

where $k_{1}$ is the elastic coefficient, $h_{T}$ is the total building height, and $\delta_{y}$ is the drift of the elastic behavior (Restrepo-Vélez and Magenes, 2004). The product of the last two values provides the height of the equivalent building $\left(h_{e}\right)$. The development of a plastic deformation occurs at a certain level, and it is assumed that the damage is concentrated in a height $\left(h_{p}\right)$. Then, the soft floor mechanism is predicted (Borzi et al., 2008). Control points $\left(\Delta_{i}\right)$ for the structure in the inelastic range is expressed as follows:

$$
\Delta_{i}=k_{1} \cdot h_{T} \cdot \delta_{y}+k_{2} \cdot h_{p} \cdot\left(\delta_{C P_{i}}-\delta_{y}\right)
$$

where $k_{2}$ is the relation between the total height of the MDOF system and the height of the equivalent SDOF system, $h_{p}$ is the height of the weakest level and where the inelastic behavior of the structure begins, and $\delta_{C P i}$ is the drift of the inelastic behavior in a certain control point. In order to define which floor of the construction will be the first to enter into an inelastic range, it

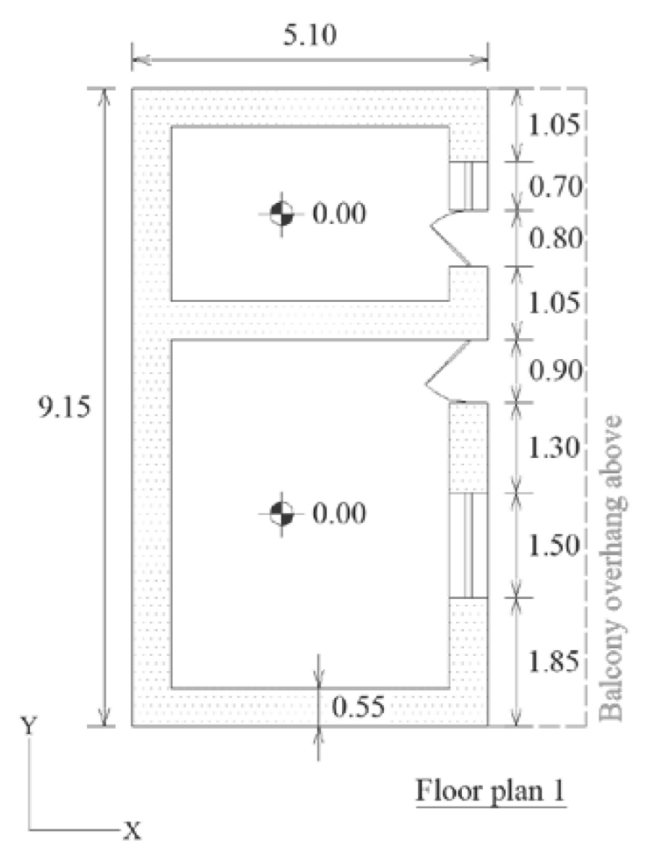

Adobe walls

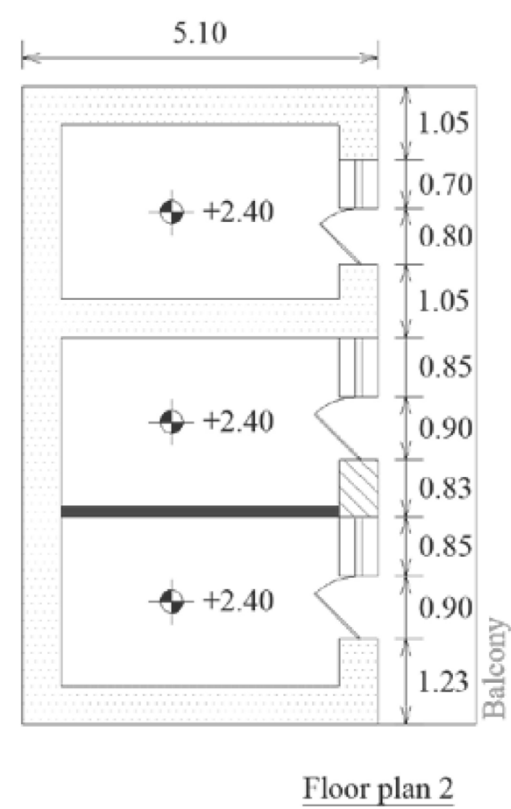

Walls with length less than $1 \mathrm{~m}$

FIGURE 3 | Plan view of the two-story adobe building. 

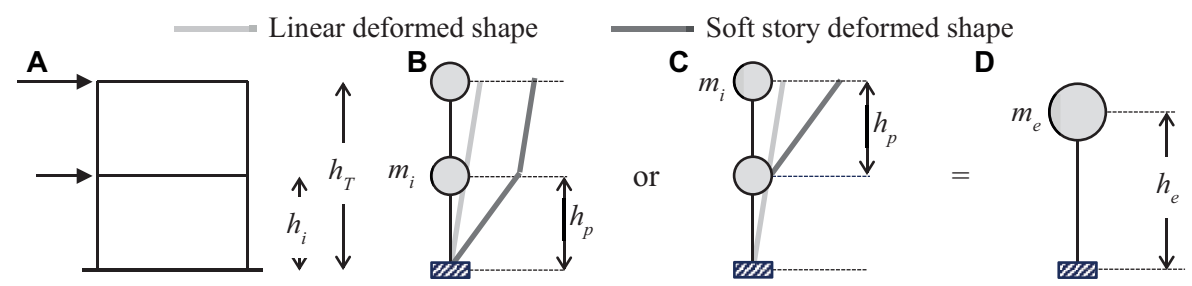

FIGURE 4 | Idealization of (A) MDOF system, (B) soft floor in first level, (C) soft floor in second level, and (D) SDOF system according to SP-BELA method.

is necessary to determine the collapse multiplier $\lambda_{i}$ in $\mathrm{X}$ and $\mathrm{Y}$ directions. For this purpose, the expression provided by Benedetti and Petrini (1984) and reported in Eq. (3) is used.

$\lambda_{i}=\frac{1}{W_{T} \cdot \frac{\sum_{k=i}^{n} h_{k} \cdot W_{k}}{\sum_{j=1}^{n} h_{j} \cdot W_{j}}} \cdot A_{i} \cdot \tau_{k i} \cdot\left[1+\frac{\sum_{k=i}^{n} W_{k}}{1.5 \cdot A_{i} \cdot \tau_{k i} \cdot\left(1+\gamma_{A B}\right)}\right]^{1 / 2}$

where $W_{T}$ is the total weight of the building, $W_{i}$ is the weight of the $i$ th floor where the soft floor is predicted, $\tau_{k i}$ is the diagonal compression resistance of the adobe at the $i$ th floor, $A_{i}$ is the total shear wall area in the direction of application of load in the ith level, $n$ is the number of stories, and $\gamma_{A B}$ is the relation between $A_{i}$ and $C_{i}$, with $C_{i}$ being the maximum area between the wall area in the loaded direction $\left(A_{i}\right)$ and the orthogonal direction $\left(B_{i}\right)$. For instance, if the analysis is in direction $\mathrm{X}$, the values of $A_{i}$ and $B_{i}$ are the product between the building surface $\left(A_{T}\right)$ and the wall percentages $\left(\rho_{X}, \rho_{Y}\right)$ such that $A_{i}=\rho_{X} \cdot A_{T}$ and $B_{i}=\rho_{Y} \cdot A_{T}$, respectively; moreover, $C_{i}=\max \left\{A_{i}, B_{i}\right\}$ and with a consideration that $i$ indicates the level where soft story was predicted, the multiplier $\lambda_{i}$ is calculated using Eq. (3); the same process is made in direction Y. However, for this direction, $A_{i}=\rho_{y} \cdot A_{T}$ and $B_{i}=\rho_{X} \cdot A_{T}$, and as a result, a new $\lambda_{i}$ is obtained and compared; the minimum value will be the collapse multiplier.

\section{Out-of-Plane Failure Mechanism}

The response of adobe buildings, when subjected to lateral loading, is also characterized by out-of-plane collapse mechanisms. These mechanisms are mainly due to the poor connection between orthogonal walls or the inadequate interaction between walls and roof system. During the occurrence of these mechanisms, the restitutive force is given by the selfweight of the wall. To describe these mechanisms, a cantilever wall and a simply supported wall, which span vertically between supports at ceiling or floor levels, can be considered; the configurations assumed for rocking to assess one- and two-story adobe buildings are shown in Figures 5A,B, respectively.

In a similar way to the in-plane failure mechanism, the capacity of a wall can be represented by means of a forcedisplacement curve of an equivalent SDOF system. This capacity curve describes the behavior caused by the seismic input into the structure. Doherty et al. (2002) idealized a non-linear SDOF model in order to analytically obtain the displacement profile of a rocking wall. In this model, walls without reinforcement could behave as rigid bodies, which are balanced at pivot points, which allowed to determine the capacity curve for out-of-plane mechanism with a bilinear force-displacement relation. For a parapet wall (Figure 5A), the pivot point is in the base, and for a simply supported wall (Figure 5B), it is assumed that the pivot points are in the base and in the wooden floor. In this approach, the restorative force is produced by the self-weight. Results in experimental F-d relationship assume a curvilinear profile, and it is observed that it varies significantly to the theoretical bilinear model; the resistance to rocking is reduced from the bilinear model to a force plateau in a trilinear model. For these reasons, the curvilinear profile can be idealized by a trilinear model as shown in Figure 6.

The bilinear curve can be defined by $F_{o}$ and $K_{o}$. The following expressions were proposed by Doherty et al. (2002) based on the boundary conditions in Figure 5.

$$
\begin{gathered}
F_{o}=M_{e} \cdot g \cdot \frac{t}{h} \\
F_{o}=4 \cdot M_{e} \cdot g \cdot \frac{t}{h}
\end{gathered}
$$

where $F_{o}$ is the force, and $g$ is the gravity. In buildings with uniformly distributed mass, the effective mass $M_{e}$ for the boundary condition used corresponds to $75 \%$ of the total mass $M$ of the wall. $K_{o}$ is the stiffness of the slope for the wall associated with F- $\Delta$, and it is defined as $1.5 M_{e}(g t / h)$ and $6 M_{e}(g t / h)$ for the boundary conditions (Figure 5), respectively.

It is observed that the relation between the experimental nonlinear curve deviates from the bilinear one (Figure 6). This is

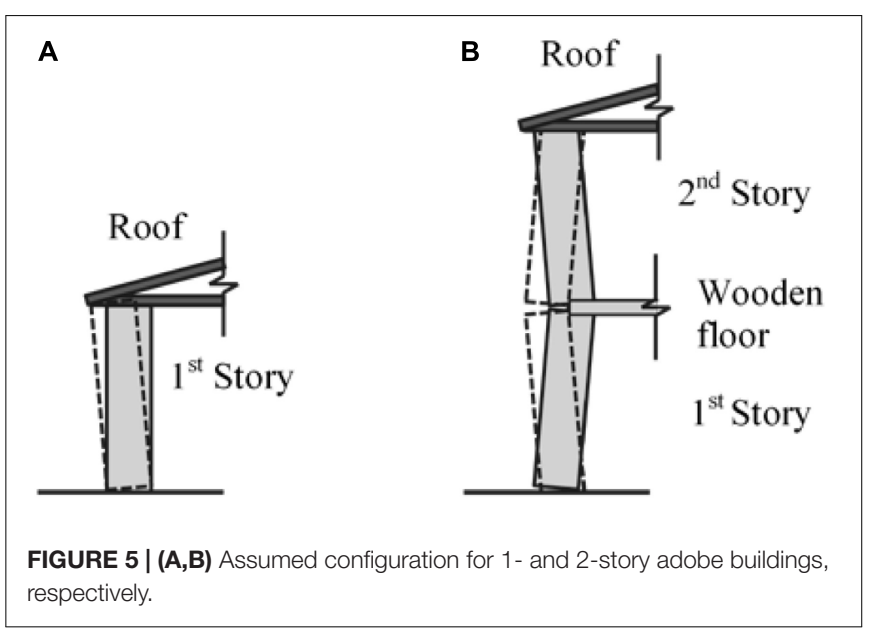


due to the non-linear deformations occurring in the mortar joint. The experimental curve can be modeled by a trilinear curve, which is defined by three parameters: $\Delta_{1}, \Delta_{2}$, and $\Delta_{u} . \Delta_{u}$ is the ultimate displacement, which means the point of static instability; if the displacement is greater than $\Delta_{u}$, the wall will collapse; $\Delta_{u}$ is considered to be $2 / 3 t$. The amplitude of the force platform is controlled by the displacement $\Delta_{2}$, and the force plateau is $\left(\Delta_{2}-\Delta_{u}\right) K_{o}$. The relations $\Delta_{1}$ and $\Delta_{2}$ are related to the properties of the materials and the state of degradation of the mortar joints. Doherty et al. (2002) suggest nominal values for the ratios $\Delta_{1} / \Delta_{u}$ and $\Delta_{2} / \Delta_{u}$ for walls in "new," "moderately," and "severely degraded," these ratios and degradation are the results of 14 simply supported walls in quasi-static and dynamic test.

\section{SEISMIC FRAGILITY ASSESSMENT}

After the generation of the initial database of the geometrical characteristics of adobe dwellings representative of the city of Cusco, a group of synthetic buildings was created by means of Monte Carlo simulations. The assessment of the seismic vulnerability of the synthetic building required determining the capacity curves associated with in-plane and out-of-plane loading conditions. For this purpose, it was necessary to define additional uncertain parameters related to mechanical properties of the material and additional variables required for the estimation of in-plane and out-of-plane capacity curves. Using a group of seismic records, it was possible to obtain the seismic demand. Finally, fragility curves were computed by comparing such capacity curves to the demand. A flowchart of the methodology used for the derivation of fragility curves is illustrated in Figure 7.

\section{Determination of Capacity Curves}

The derivation of fragility curves for the seismic vulnerability of adobe dwellings in the city of Cusco required the estimation of their structural performance. In this sense, the in-plane and out-of-plane responses of this type of buildings were evaluated by means of bilinear and trilinear capacity curves, respectively. In addition, these capacity curves required the definition of uncertain parameters, which are associated with

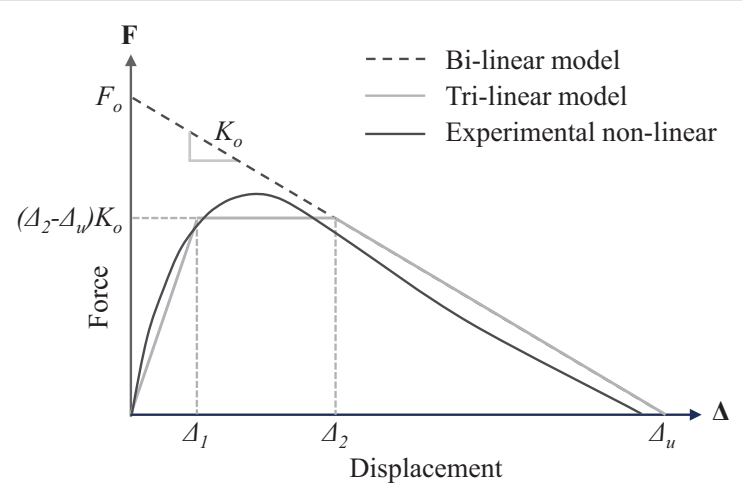

FIGURE 6 | Force-displacement relationship for out-of-plane. Adapted from Doherty (2000) with permission from K. Doherty.

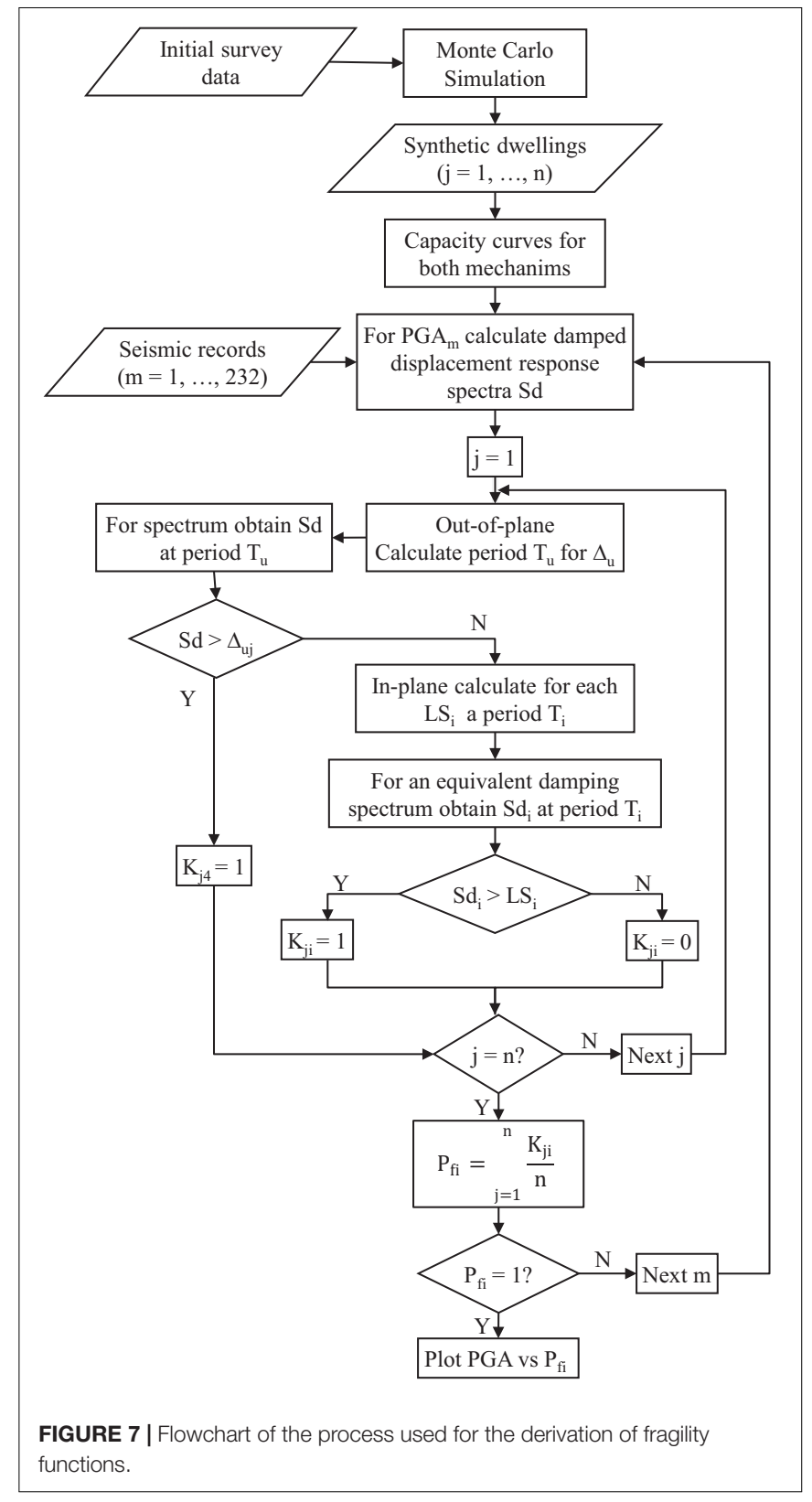

geometrical and mechanical properties of these buildings. During the building survey, all geometrical variables that were involved in the analysis, together with their corresponding statistical characteristics, were properly identified. It is worth noting that all the statistical characteristics of some uncertain parameters such as mechanical properties of adobe, death load, and live load in floor and roof were not obtained from the building survey. Therefore, it was necessary to define these properties based on values reported in literature. For instance, the diagonal compressive strength of adobe masonry $\tau_{k i}$ was obtained from the investigation conducted by Tarque et al. (2012). The remaining parameters were defined, taking into consideration the Peruvian code E-020 (NTC E.020, 2006). These additional uncertain parameters, as well as their corresponding 
TABLE 2 | Parameters used for the estimation of the capacity curves of the synthetic buildings.

\begin{tabular}{llccc}
\hline Variable & Description & Units & $\boldsymbol{\mu}$ & $\boldsymbol{\sigma}$ \\
\hline$\gamma_{a}$ & Specific weight of adobe & $\mathrm{kN} / \mathrm{m}^{3}$ & 16 & 2.5 \\
$\tau_{k i}$ & Shear resistance of masonry adobe walls & $\mathrm{N} / \mathrm{m}^{2}$ & 4000 & 500 \\
$\gamma_{w}$ & Specific weight of wood & $\mathrm{kN} / \mathrm{m}^{3}$ & 10 & 0.5 \\
$\gamma_{t}$ & Specific weight of tiles & $\mathrm{kN} / \mathrm{m}^{3}$ & 16 & 0.5 \\
$L_{f}$ & Live load in floor & $\mathrm{N} / \mathrm{m}^{2}$ & 2000 & 200 \\
$L L_{r}$ & Live load in roof & $\mathrm{N} / \mathrm{m}^{2}$ & 1000 & 200 \\
$D L_{f}^{*}$ & Dead load in floor & $\mathrm{N} / \mathrm{m}^{2}$ & 550 & 100
\end{tabular}

${ }^{*} \mu$ represents the value for a wooden floor joist with logs (diameter of $100 \mathrm{~mm}$ ) distributed every $0.50 \mathrm{~m}$ and the tongue-and-groove floor over this.

statistical characteristics, are summarized in Table 2 . The probability density function defined for all uncertain parameters corresponded to a normal function because it was assumed that it fitted better to the data obtained from the surveys.

Monte Carlo simulations were used to create 1,000 synthetic dwellings, keeping the initial statistical properties and considering that these statistical properties were truncated at $80 \%$ for more reliable results. The variables $k_{1}$ and $k_{2}$ presented a deterministic behavior, and they were calculated using the expressions reported by Restrepo-Vélez (2003). For one-story adobe dwellings, the average value for $k_{1}$ is 0.79 , and the value of $k_{2}$ is 0.97 . In the case of two-story dwellings, the values of $k_{1}$ and $k_{2}$ presented values of 0.72 and 0.95 , respectively. Figure 8 shows the capacity curves for the 1,000 synthetic buildings. The collapse multipliers of one-story dwellings range between 0.3 and 0.7. Figure 8A also shows the elastic and the collapse limits with average values of 1.2 and $12.2 \mathrm{~mm}$, respectively. Considering that the average height is $2.47 \mathrm{~m}$, the drifts for elastic and collapse limits correspond to 0.049 and $0.49 \%$, respectively. Similarly, in Figure 8B, the collapse multipliers associated with two-story buildings range between 0.25 and 0.4 , whereas the mean of elastic and collapse limits are 1.9 and $12.8 \mathrm{~mm}$, and with an average height of $2.46 \mathrm{~m}$ for two-story, the drifts are 0.077 and $0.52 \%$, respectively.

The seismic vulnerability assessment also required the definition of capacity curves associated with the out-of-plane response of the synthetic adobe dwellings. In this process, considering the boundary conditions (Figures 5A,B) and using Eqs. (4) and (5), it was possible to obtain a bilinear relation. For this purpose, it was necessary to obtain the displacement capacity that is a function of the wall thickness $t$. In the present work, the ratios are considered severely degraded because of the fact that the units of adobe are joined by mud mortar. In addition, in some walls, there is no protection at the base (pivot point), and they are exposed to the rain effects that degraded the effective width. Another consideration is that the main age of adobe dwelling surveys is 28 years, which means that there is an important degradation of the mortar joints. The values for the previous consideration suggested by Doherty et al. (2012) were 0.20 for $\Delta_{1} / \Delta_{u}$ and 0.50 for $\Delta_{2} / \Delta_{u}$, respectively. Capacity curves are represented with a seismic coefficient, which is the ratio of the horizontal force $\left(F_{o}\right)$ and the wall weight. Figure 9A shows the value of seismic coefficient that ranges between 0.05 and 0.1 for one-story dwellings, whereas the seismic coefficient for twostory varies between 0.13 and 0.17 (Figure 9B). Both cases present results according to what it was expected: the seismic coefficients for two-story buildings are greater than those related to one-story dwellings; the model in Doherty et al. (2002) indicates that for a supported wall $F_{o}$ is greater than for a parapet wall.

\section{Derivation of Fragility Curves}

In this stage, with the data of synthetic buildings and their respective capacity curves, it is important to evaluate the performance of these buildings using the seismic demand, which is a representation of the earthquake ground motion (seismic input). In this process, the effect of the record-torecord variability of the seismic input was used in order to get realistic results (Lovon et al., 2018). The city of Cusco is located in an area where, due to presence of geological faults, the main seismogenic source produces cortical earthquakes. The shallowness of this type of earthquakes produces damage that resembles seismic events occurring because of a subduction process (Tavera, 2017). Then, because of the lack of records for the main source for Cusco, a database of 232 ground motions, which were recorded from subduction mechanism by the Pacific Earthquake Engineering Research Center (PEER), was selected for this investigation (for further details see
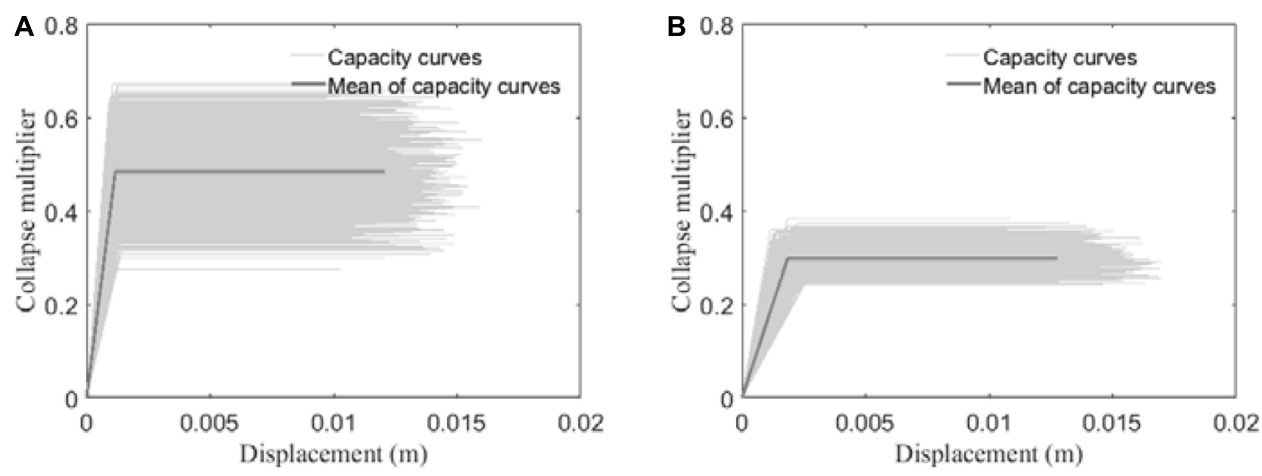

FIGURE 8 | Capacity curves associated with in-plane mechanisms: (A) one- and (B) two-story adobe dwellings. 

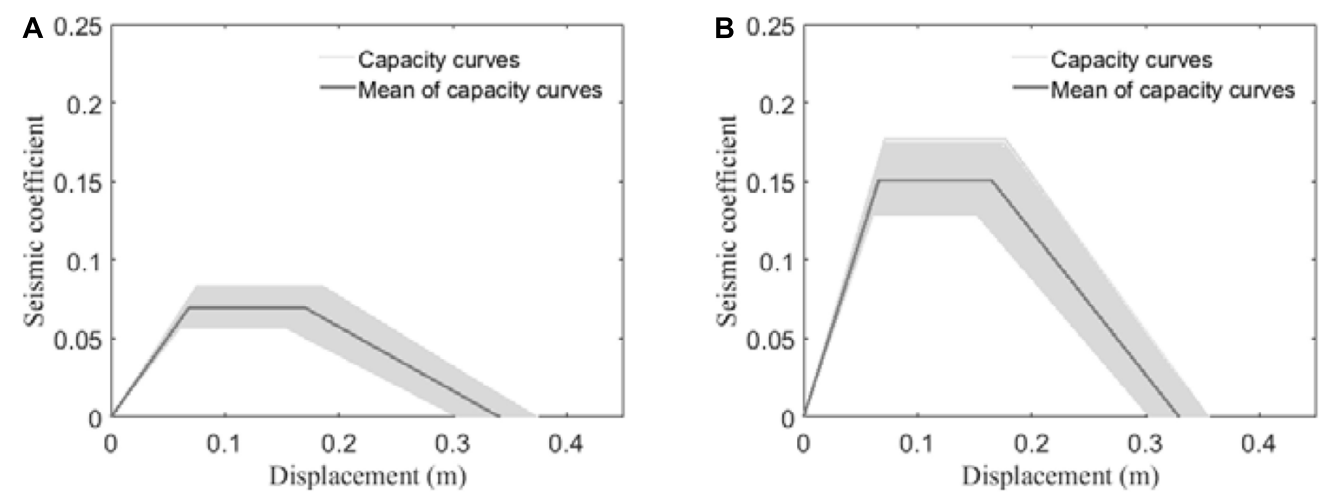

FIGURE 9 | Capacity curves associated with out-of-plane mechanisms: (A) one- and (B) two-story adobe dwellings.

Lovon et al., 2018). This database contains a great variety of local seismic hazard characteristics such as magnitude, range of accelerations, frequency content, and duration that may represent an earthquake at the Peruvian Coast and could also affect Cusco. Figure 10 shows the pseudospectral accelerations for all the records that have magnitudes between 5 and 9 Mw. The soil factor is considered for rock soil because of origin of the records.

Based on the method proposed by Silva et al. (2013), it was necessary to calculate the displacement demand for each LS. First, the demand for in-plane mechanism was calculated using the equivalent viscous damping $\xi_{L S i}$ for each LS. This equivalent damping was obtained using the expression reported in Eq. (6) as proposed by Calvi (1999):

$$
\xi_{L S i}=a \cdot\left(1-\frac{1}{\left(\mu_{L S i}\right)^{b}}\right)+\xi_{e l}
$$

where $\xi_{e l}$ is the damping for the elastic response that is equal to $5 \%$; $\mu_{L S i}$ is the displacement ductility for the $i$ th LS, whereas

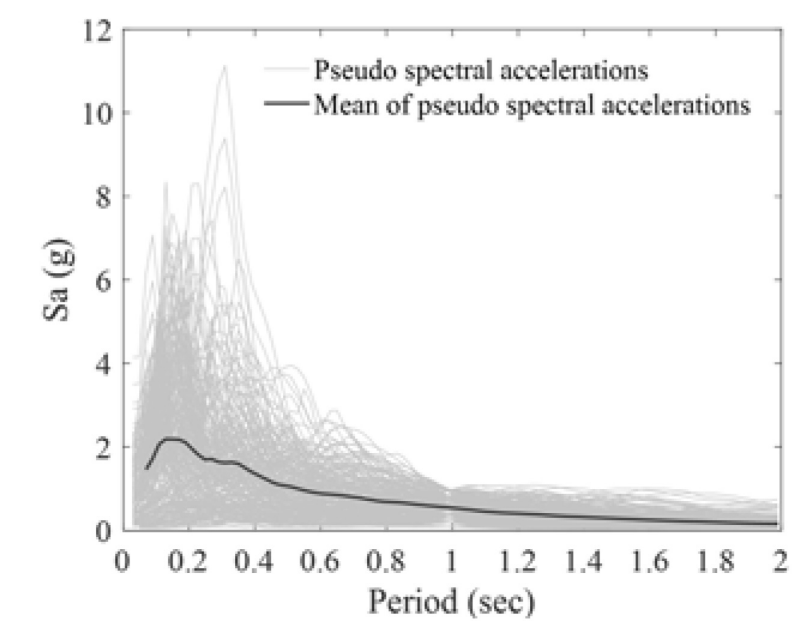

FIGURE 10 | Pseudospectral acceleration for the 232 records from subduction.

$a$ and $b$ are two coefficients [both depending on the hysteretic properties of the structure (Tarque et al., 2012)] with values of 25 and 0.5 , respectively. For the derivation of the fragility curves, it was necessary to establish the damage thresholds based on the LS. Table 3 shows the damage states proposed by Tarque et al. (2012). On the other hand, according to Griffith et al. (2003), the evaluation of the out-of-plane response does not require changing the $5 \%$ damped elastic displacement response spectrum, and the unique threshold is collapsed.

Restrepo-Vélez and Magenes (2004) proposed Eq. (7) for inplane in order to obtain the period $(T)$ for each $\operatorname{LS}_{\mathrm{i}}$, being $\lambda$ the minimum collapse multiplier calculated with Eq. (3):

$$
T_{i}=2 \pi \cdot \sqrt{\frac{L S_{i}}{\lambda \cdot g}}
$$

In out-of-plane, it is necessary to use a secant stiffness $\left(K_{e f}\right)$ in order to represent a substitute structure of an MDOF system. The $K_{e f}$ is obtained from force-displacement curve corresponding to the point of maximum displacement $\left(\Delta_{2}\right)$, which is described in Doherty et al. (2002) as the point with more consistent notion. The $K_{e f}$ for the equivalent SDOF system is obtained by the following:

$$
K_{e f}=K_{o} \cdot\left(\frac{\Delta_{2}-\Delta_{u}}{\Delta_{2}}\right)
$$

where $K_{o}$ is the average secant stiffness (Figure 6). Hence, the period for out-of-plane is obtained by the following expression:

$$
T=2 \pi \cdot \sqrt{\frac{M_{e}}{K_{e f}}}
$$

TABLE 3 | Damage thresholds associated with limit state.

Limit state

LS1 - light damage

LS2 - moderate damage

LS3-extensive damage

LS4-collapse
Damage threshold

$0.75 * \mathrm{CP}_{1}$

$1.9 * \mathrm{CP}_{1}$

$\mathrm{CP}_{2}$

$\mathrm{CP}_{3}$ 

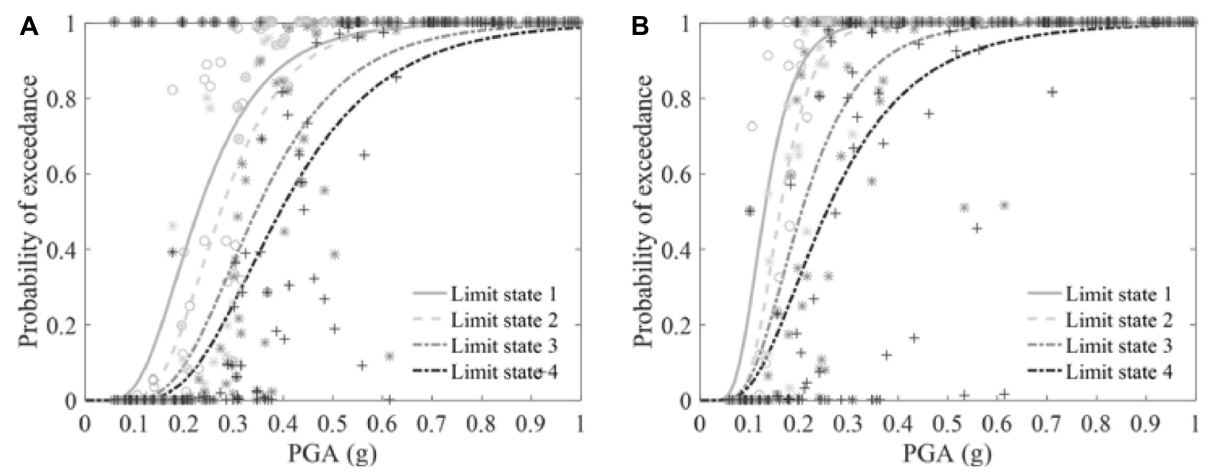

FIGURE 11 | Combined fragility curves for in-plane and out-of-plane associated with (A) one- and (B) two-story adobe dwellings.

Initially, the capacity curves for both mechanisms were obtained for all the synthetic dwellings. Each dwelling was evaluated for a sequence of records in order to obtain its seismic performance; thus, when the seismic demand exceeded a certain LSs, it was progressively recorded in the DPM until a record exceeded an LS4. The process started by evaluating initially the out-of-plane mechanism. It was possible to recognize the performance of the dwelling by comparing the demand and the displacement. In case the demand exceeded $\Delta_{u}$, then the structure collapsed; otherwise, the dwelling was capable of withstanding the load, and the analysis continued with the assessment of the in-plane mechanism in which the demand was compared to the capacity for the different LSs. Subsequently, the DPM was assembled progressively after all synthetic buildings were subjected to all the records. From the DPM, it was possible to obtain the Cumulative Probability Damage Matrix (CDPM), which is interpreted as a point cloud that indicates the percentage of exceeding an LS. Finally, the point cloud was adjusted to an accumulated log-normal function and fragility curves obtained (Figure 11). According to Ericksen et al. (1954), the 1950's Cusco earthquake had a peak ground acceleration (PGA) of $0.3 \mathrm{~g}$. Then, the probability of exceeding the collapse state for this earthquake is 30 and $60 \%$ for 1 - and 2 -story buildings, respectively, according to the computed fragility functions.

\section{CONCLUSION}

The objective of the research was to derive fragility curves for one- and two-story adobe buildings in Cusco, using the SP-BELA method proposed by Borzi et al. (2008). One of the modifications applied to such methodology allowed the development of combined in-plane and out-of-plane fragility curves. The importance of these functions relies on the combination of both failure mechanisms, which is usually addressed using logic trees, and in the current work, it is implemented by analyzing both mechanism in the sample of buildings. The probabilistic work carried out allows covering the uncertainty of the material and the geometric characteristics of the constructions.

The adobe buildings around the city of Cusco need to improve their seismic performance by means of external reinforcement.
For a PGA value of $0.3 \mathrm{~g}$, approximately 30 and $60 \%$ of collapse is expected in one- and two-story buildings, respectively. The $0.3 \mathrm{~g}$ is the maximum horizontal acceleration expected to occur in Cusco over soil type $2\left(V_{s}\right.$ between 180 and $500 \mathrm{~m} / \mathrm{s}$ ) according to the Peruvian Seismic Code E-030 (NTC E.030, 2018) (return period of 475 years). This assessment may not be applicable to dwellings composed of mixed materials as stone and adobe, basically located at the historic center, and they may need another approach.

For a further study, it is necessary to assess fragility curves with records of Cusco. The database of PEER for subduction was used to evaluate the seismic hazard in the area in study because of a lack of records.

Based on the obtained fragility curves, it was possible to generate vulnerability curves that may help decision makers to create efficient contingency plans. This work can also be extended to all the adobe dwellings that maintain a similar characterization in the Peruvian Andes.

\section{DATA AVAILABILITY STATEMENT}

The datasets generated for this study are available on request to the corresponding author.

\section{AUTHOR CONTRIBUTIONS}

GS performed the field evaluation with the data interpretation. HL and NT followed the analyses interpretation and the conceptual evaluation of the fragility curves, also studied by GS and corrected by CC. Finally, CC contributed also to the results interpretation.

\section{ACKNOWLEDGMENTS}

The authors wish to express their gratitude to all the persons who were involved in this work, especially to the persons who helped and made possible to obtain the survey data. 


\section{REFERENCES}

Ahmad, N., Crowley, H., Pinho, R., and Ali, Q. (2011). "Displacement-based Earthquake loss assessment of adobe buildings of Pakistan," in Modern Methods and Advances in Structural Engineering and Construction, eds S. O. Cheung, S. Yazdani, N. Ghafoori, and A. Singh (Wuhan: Research Publishing).

Benedetti, D., and Petrini, V. (1984). Sulla vulnerabilità sismica di edifice in muratura: proposta su un metodo di valutazione. Lindustria Delle Costruzioni 149, 66-74.

Bernardini, A., Gori, R., and Modena, C. (1990). “An application of coupled analytical models and experimental knowledge for seismic vulnerability analyses of masonry buildings," in Engineering Aspects of Earthquake Phenomena, ed. A. Kortize (Oxon: INEEC), 161-180.

Borzi, B., Crowley, H., and Pinho, R. (2008). Simplified Pushover-Based Earthquake Loss Assessment (SP-BELA) Method for masonry buildings. Int. J. Arch. Heritage 2, 353-376.

Briceño, C., Moreira, S., Noel, M., Gonzales, M., Vila-Chã, E., and Aguilar, R. (2019). Seismic vulnerability assessment of a 17th century adobe church in the peruvian andes. Int. J. Arch. Heritage 13, 140-152. doi: 10-1018/15583058.2018. 1497224

Calvi, G. M. (1999). A displacement-based approach for vulnerability evaluation of classes of buildings. J. Earthquake Eng. 3, 411-438.

Chieffo, N., Clementi, F., Formisano, A., and Lenci, S. (2019). Comparative fragility methods for seismic assessment of masonry buildings located in Muccia (Italy). J. Build. Eng. 25:100813. doi: 10.1016/j.jobe.2019.100813

Chieffo, N., and Formisano, A. (2019). Comparative seismic assessment methods for masonry building aggregates: a case study. Front. Built Environ. 5:123. doi: 10.3389/fbuil.2019.00123

Cosenza, E., Manfredi, G., Polese, M., and Verderame, G. M. (2005). A multi-level approach to the capacity assessment of existing RC buildings. J. Earthquake Eng. 9, 1-22.

Crowley, H., Pinho, R., and Bommer, J. J. (2004). A probabilistic displacementbased vulnerability assessment procedure for earthquake loss estimation. Bull. Earthquake Eng. 2, 173-219.

D’Ayala, D., and Speranza, E. (2002). “An integrated procedure for the assessment of seismic vulnerability of masonry structures," in Proceeding of the Twelfth European Conference on Earthquake Engineering, London.

Doherty, K. (2000). An Investigation of the Weak Links in the Seismic Load Path of Unreinforced Masonry Buildings. PhD Thesis, Adelaide University, Adelaide.

Doherty, K. T., Griffith, M. C., Lam, N., and Wilson, J. (2002). Displacementbased seismic analysis for out-of-plane bending of unreinforced masonry walls. Earthquake Eng. Struct. Dyn. 31, 833-850.

Ericksen, G., Fernandez, J., and Silgado, E. (1954). The Cusco, Peru, earthquake of May 21, 1950. Bull. Seismol. Soc. Am. 44, 97-112.

Formisano, A., Chieffo, N., and Mosoarca, M. (2017). Seismic vulnerability and damage speedy estimation of an urban sector within the municipality of San Potito Sannitico (Caserta, Italy). Open Civil Eng. J. 11, 1106-1121.

Fuentes, D., Laterza, M., and D’Amato, M. (2019). "Seismic vulnerability and risk assessment of historic constructions: the case of masonry and adobe churches in Italy and Chile (2029) RILEM bookseries," in Proceedings of the 11th International Conference on Structural Analysis of Historical Constructions, Cusco, 1127-1137.
Griffith, M., Magenes, G., Melis, G., and Picchi, L. (2003). Evaluation of out-ofplane stability of unreinforced masonry walls subjected to seismic excitation. J. Earthquake Eng. 7, 141-169.

Lovon, H., Tarque, N., Silva, V., and Yepes-Estrada, C. (2018). Development of fragility curves for confined masonry buildings in Lima, Peru. Earthquake Spect. 34, 1339-1361.

Montesinos, M. (2016). Caracterización Mecánica de Componentes Estructurales en Construcciones Arqueológicas de Tierra: El caso de Huaca de la Luna (in Spanish). Master thesis, Pontificia Universidad Católica del Perú, Peru.

Neves, F., Costa, A., Vicente, R., Oliveira, C. S., and Varum, H. (2012). Seismic vulnerability assessment and characterisation of the buildings on Faial Island, Azores. Bull. Earthquake Eng. 10, 27-44. doi: 10.1007/s10518-0119276-0

NTC E.020 (2006). - Norma técnica de edificación. Cargas (in Spanish). Lima: MTC/SENCICO.

NTC E.030 (2018). - Norma técnica de edificación. Diseño Sismoresistente (in Spanish). Lima: MTC/SENCICO.

Restrepo-Vélez, L. F. (2003). A Simplified Mechanics-Based Procedure for the Seismic Risk Assessment of Unreinforced Masonry Buildings. Individual Study. Pavia: ROSE School.

Restrepo-Vélez, L. F., and Magenes, G. (2004). "Simplified procedure for seismic risk assessment of unreinforced masonry buildings," in Proceedings of the Thirteenth World Conference on Earthquake Engineering, Vancouver.

Silva, V., Varum, H., Crowley, H., and Pinho, R. (2013). "Extending displacementbased earthquake loss assessment (DBELA) for the computation of fragility curves," in Proceedings of the 15th World Conference on Earthquake Engineering, Lisboan.

Tarque, N., Crowley, H., Pinho, R., and Vanum, H. (2012). Displacement-based fragility curves for seismic assessment of adobe buildings in Cusco, Perú. Earthquake Spect. 28, 759-794.

Tavera, H. (2017). Actualización Del Escenario Por Sismo, Tsunami y Exposición en la Región Central Del Perú in Spanish. Available online at: http://repositorio. igp.gob.pe/handle/IGP/781 (accessed August 23, 2019).

Vicente, R., Parodi, S., Lagomarsino, S., Varum, H., and Silva, J. A. R. M. (2011). Seismic vulnerability and risk assessment: case study of the historic city centre of Coimbra, Portugal. Bull. Earthquake Eng. 9, 1067-1096. doi: 10.1007/s10518010-9233-3

Villar-Vega, M., Silva, V., Crowley, H., Yepes, C., Tarque, N., and Acevedo, A. B. (2017). Development of a fragility model for the residential building stock in South America. Earthquake Spect. 33, 581-604.

Conflict of Interest: The authors declare that the research was conducted in the absence of any commercial or financial relationships that could be construed as a potential conflict of interest.

Copyright (c) 2020 Sumerente, Lovon, Tarque and Chácara. This is an open-access article distributed under the terms of the Creative Commons Attribution License (CC BY). The use, distribution or reproduction in other forums is permitted, provided the original author(s) and the copyright owner(s) are credited and that the original publication in this journal is cited, in accordance with accepted academic practice. No use, distribution or reproduction is permitted which does not comply with these terms. 